\title{
Prevalence of Mycoplasma pneumoniae infection in pediatric patients with acute asthma exacerbation
}

\author{
Elias Kassisse, M.D., ${ }^{a}$ Hecmary García, M.D., ${ }^{b}$ Linair Prada, M.D., ${ }^{b}$ \\ Ixora Salazar, M.D. ${ }^{b}$ and Jorge Kassisse, M.D.c
}

\begin{abstract}
Introduction. Mycoplasma pneumoniae may be involved in refractory asthma exacerbation.

Objective. To determine the prevalence of Mycoplasma pneumoniae infection in patients with acute asthma exacerbation.

Material and method. A prospective, crosssectional, observational, case-control study was carried out in patients older than 2 years old and younger than 12 . Immunoglobulin $\mathrm{M}(\mathrm{IgM})$ antibodies were serologically determined for $M$. pneumoniae, using the NovaLisa ${ }^{\circledR}$ NovaTeckit for enzyme-linked immunosorbent assay (ELISA). Test results $\geq 11$ NTU (NovaTec units) were regarded as positive. The statistical analysis was performed by means of the analysis of variance (ANOVA) and the $\chi^{2}$ test, with a significance level of $\mathrm{p}<0.05$.

Results. One hundred and eighty children were studied, of which 130 had asthma and 50 comprised the control group. Specific IgM was positive for 60 patients, that is $46.15 \%$ of the asthmatic children $(p<0.001)$. The severity of the exacerbation was directly related to IgM levels $(p<0.001)$. Hospitalization rate was $75 \%$, and it was significantly associated to specific IgM levels $(\mathrm{p}<0.001)$. Conclusion. Our data suggest that children with acute asthma show a high prevalence $(46 \%)$ of Mycoplasma pneumoniae infection and that there is a close relation between severe acute asthma exacerbation and the presence of Mycoplasma pneumoniae infection. These findings might result in therapeutic implications centered in the use of specific antibiotics to fight this atypical organism. Keywords: acuteasthma, exacerbation, Mycoplasma pneumoniae.
\end{abstract}

a. Hospital "Dr. Santos

Service, "Hospital

Universitario

Antonio Patricio de

Alcalá", Cumaná.

c. Type I Hospital

"Dr. Alberto

Musa Yibirin", El

Pilar. Sucre state,

Venezuela.

E-mail address:

Elías Kassisse, M.D.:

ekassisse@gmail.com

Funding:

None

Conflict of interest:

None.

Received: 12-20-2016

Accepted: 10-10-2017

\section{INTRODUCTION}

The relationship between respiratory infections and asthma development or exacerbation in both children and adults has been well established. Many of these events are basically caused by viral infections. ${ }^{1-3}$

Contrary to what happens with viruses, the relationship with atypical respiratory infections has not been completely established and is under investigation, not only in the case of exacerbation, but also as regards asthma development, persistence and severity. ${ }^{4-7}$

On the one side, acute or previous infection by M. pneumoniae (MP) is more frequent in children and adults with asthma than in patients without asthma. On the other side, MP may be involved in refractory asthma exacerbations, and failure to identify it increases morbidity and, potentially, mortality. ${ }^{8}$

The purpose of this study was to establish the prevalence of MP infection in patients with acute asthma exacerbation.

\section{MATERIALS AND METHODS}

A prospective, cross-sectional, observational, case-control study was carried out in the pediatric emergency department of the Autonomous Service of the "Hospital Universitario Antonio Patricio de Alcalá", Cumaná,
To cite: Kassisse E, García H, Prada L, et al. Prevalence of Mycoplasma pneumoniae infection in pediatric patients with acute asthma exacerbation. Arch Argent Pediatr 2018;116(3):179-185. Sucre, Venezuela, from February, 2015 to July, 2016.

In a consecutive fashion, patients $>2$ and $<12$ years old with asthma exacerbation seen in our hospital were included in the study.

Patients who had been previously diagnosed with asthma or who had suffered at least three exacerbations, and whose condition had improved 
with the use of bronchodilators, were considered asthmatic.

Children with heart, kidney or immune conditions, as well as concomitant hematologic conditions, were excluded; and so were those patients who had received macrolids within the previous 4 weeks.

Asthma exacerbation was defined as the patient presenting one or a combination of the following signs and symptoms: a sudden or progressive event of cough, respiratory distress, wheezing or chest pain.

Subjects selected as controls were healthy children $>2$ and $<12$ years old, without respiratory symptoms, not asthmatic, and who had not received macrolids for at least 4 weeks. They were selected from the Hospital's pediatric office.

The study was assessed and approved by the Hospital's Postgraduate Education Commission, which ensured the ethical aspects were met in accordance with the Declaration of Helsinki standards.

All the study subjects were requested to sign an informed consent.

Asthmatic exacerbation severity was measured using the Wood-Downes scale, as modified by Ferrés, including 6 parameters. A score of $<3$ points described mild asthma exacerbations; between 4 and 7 points, moderate exacerbations; and $>7$ points indicated severe exacerbations. ${ }^{9}$

A sudden-onset crisis was one that presented within the first three hours of a medical visit, and a late-onset crisis, that which required more time.

The investigators did not participate in therapeutic decision-making.

A case report card specially designed for the collection of demographic, clinical and lab data was used.

The socioeconomic stratification of the study population was determined using the GraffarMéndez level scale, with stratum I being the highest level, and strata IV/V, the lowest and, therefore, the lowest socioeconomic status. ${ }^{10}$

A $2 \mathrm{~cm}^{3}$ blood sample from a superficial vein of the forearm was obtained from each patient and each control in order to perform a serological study of MP immunoglobulin M (IgM) antibodies. The samples were analyzed by means of the qualitative immunoenzymatic determination of specific MP antibodies using the NovaLisa ${ }^{\circledR}$ NovaTec Immundiagnostica $\mathrm{GmbH}$ kit for the enzyme-linked immunosorbent assay (ELISA). Positive test results were those $\geq 11$ NTU (NovaTec units) obtained in a single determination, as per the manufacturer's specifications, with $95 \%$ sensitivity and specificity.

The primary outcome measure (purpose of the study), were specific IgM levels and their relationship with the exacerbation severity, and secondary outcome measure was the hospitalization rate.

To determine the significance of the relationship between the categorical outcome measures and the positivity of the specific IgM test, a statistical analysis was performed through the $\chi^{2}$ test.

In order to determine the relationship between the different levels of specific IgM and the presence of fever, the severity of the exacerbation, time since asthma diagnosis, time of crisis onset and hospitalization, the one-way analysis of variance (ANOVA) was used. Once the differences were found, the analysis was followed by the Student-Newman-Keuls (SNK) test at $95 \%$.

Statistical significance was set at $\mathrm{p}<0.05$.

\section{RESULTS}

One hundred and eighty subjects were studied, of which 130 had asthma and 50 comprise the control group. Average age ( \pm standard deviation [SD]) was $4.9 \pm 1.2$ years old. Fifty three percent were females. Ninety seven percent were on Graffar's strata III-IV (87 [48.3\%] and 88 [48.9\%] subjects, respectively). Serum level of specific IgM was $8.66 \pm 5.77$ NTU.

Table 1 summarizes the general characteristics of the population of children with acute asthma exacerbation and children in the control group. No differences between the average age $( \pm S D$ ) and the distribution by gender were observed. Ninety two percent of the children in the control group and $99 \%$ of the asthmatic children were in strata III and IV. Specific IgM levels were much higher among asthmatic children than among children in the control group (10.79 \pm 5.406 vs. $3.11 \pm 1.262$ NTU, respectively).

Table 2 describes the characteristics of the 130 asthmatic children studied.

Specific IgM was positive in 60 patients, which implies a $46 \%$ prevalence. Prevalence in children 2-6 years old (37.69\%) was higher than prevalence in children $>6$ years old $(8.46 \%)$. However, no significant differences were observed between specific IgM positivity and age $\left(\chi^{2}=0.00\right.$, not significant [NS]; $\chi_{(1 ; 0.05)}^{2}=3.841$ [with Yates' correction]).

The ANOVA and the subsequent analysis 
(SNK at $95 \%$ ) revealed highly significant differences between the asthmatic patients and the control group $(\mathrm{p}<0.001)$. Asthmatic children showed much higher specific IgM levels (Figure 1).

Asthmatic children who developed fever and cough during the exacerbation course presented higher, statistically significant IgM levels $(\mathrm{p}=0.0000$, both for fever and cough).

The relationship between the severity of the exacerbation and the specific IgM levels could be observed through the ANOVA and the SNK
95\% analyses-acute asthma patients showed the highest levels $(\mathrm{p}=0.0000)$ (Table 3$)$.

Seventy six percent of study children had been diagnosed with asthma less than 2 years ago. The ANOVA did not show any statistical significance between the time since diagnosis and serum levels of specific $\operatorname{IgM}(p=0.3430)$.

Both the crisis onset (sudden vs. late) and the hospitalization rate were related to specific IgM levels. The existing relationship between specific IgM and the outcome measures previously described are summarized in Table 3.

TABLE 1. General characteristics of the study population

\begin{tabular}{lccc}
\hline Outcome measures $^{*}$ & $\begin{array}{c}\text { All subjects } \\
(\mathrm{n}=180)\end{array}$ & $\begin{array}{c}\text { Control subjects } \\
(\mathrm{n}=50)\end{array}$ & $\begin{array}{c}\text { Asthmatic } \\
(\mathrm{n}=130)\end{array}$ \\
\hline Age (years) & $4.9 \pm 1.92(2-12)$ & $4.6 \pm 1.65(3-10)$ & $5.0 \pm 2.01(2-12)$ \\
Gender (M/F) & $84 / 96$ & $24 / 26$ & $60 / 70$ \\
Graffar\# & $4(2.2)$ & $3(6.00)$ & $1(0.7)$ \\
II & $87(48.3)$ & $20(40.0)$ & $67(51.5)$ \\
III & $88(48.9)$ & $24(48.0)$ & $62(47.7)$ \\
IV & $1(0.6)$ & $1(2.00)$ & - \\
V & $8.66 \pm 5.77(1.0-25.2)$ & $3.11 \pm 1.26(1.0-6.0)$ & $10.79 \pm 5.406(1.4-25.2)$ \\
IgM (NTU)
\end{tabular}

* Age and IgM data are presented as means. standard deviation and ranges; n (\%)

\#: Correspond to socioeconomic levels. ${ }^{* *}$ NTU: NovaTec units.

M: masculine; F: feminine; IgM: immunoglobulin M.

TABLE 2. Characteristics of patients with acute exacerbation

\begin{tabular}{|c|c|c|c|}
\hline \multirow[t]{2}{*}{ Outcome measures ${ }^{*}$} & \multirow{2}{*}{$\begin{array}{l}\text { All subjects } \\
\text { 2-12 years old } \\
(n=130)\end{array}$} & \multicolumn{2}{|c|}{ Age groups } \\
\hline & & $\begin{array}{c}2-6 \text { years old } \\
(n=106)\end{array}$ & $\begin{array}{l}7-12 \text { years old } \\
(n=24)\end{array}$ \\
\hline Fever (yes/no) & $20 / 110(15.38 / 84.62)$ & $16 / 90(12.31 / 69.23)$ & $4 / 20(3.08 / 15.38)$ \\
\hline Cough (yes/no) & $51 / 79(39.23 / 60.77)$ & $36 / 70(27.69 / 53.85)$ & $15 / 9(11.54 / 6.92)$ \\
\hline \multicolumn{4}{|l|}{ Severity } \\
\hline Mild & $26(20.00)$ & $22(16.92)$ & $4(3.08)$ \\
\hline Moderate & $98(75.38)$ & $79(60.77)$ & $19(14.62)$ \\
\hline Severe & $6(4.62)$ & $5(3.85)$ & $1(0.77)$ \\
\hline $\operatorname{IgM}(\mathrm{NTU})^{\star *}$ & $10.79 \pm 5.406(1.4-25.2)$ & $10.84 \pm 5.312(1.4-25.2)$ & $10.58 \pm 5.919(2.4-22.2)$ \\
\hline Positive & $60(46.15)$ & $49(37.69)$ & $11(8.46)$ \\
\hline Negative & $70(53.85)$ & $57(43.85)$ & $13(10.0)$ \\
\hline \multicolumn{4}{|l|}{ Time since diagnosis } \\
\hline$<1$ years & $13(10.00)$ & $6(4.62)$ & $7(5.38)$ \\
\hline 2 years & $73(56.15)$ & $65(50.00)$ & $8(6.15)$ \\
\hline$\geq 3$ years & $44(33.85)$ & $35(26.92)$ & $9(6.92)$ \\
\hline \multicolumn{4}{|l|}{ Crisis onset } \\
\hline$\leq 3$ hours & $87(66.92)$ & $70(53.85)$ & $17(13.08)$ \\
\hline$\geq 3$ hours & $43(33.85)$ & $36(27.69)$ & $7(5.38)$ \\
\hline \multicolumn{4}{|l|}{ Hospitalization } \\
\hline Yes & $97(74.62)$ & $80(61.54)$ & $17(13.08)$ \\
\hline No & $33(25.38)$ & $26(20.00)$ & $7(5.38)$ \\
\hline
\end{tabular}

* Data are presented as means. standard deviation and ranges; $\mathrm{n}(\%)$

${ }^{* *}$ NTU: NovaTec units. 
The outcome measures analysis by means of the $\chi^{2}$ test did not show any statistical relationship between positivity and age, though there were differences for gender distribution, since positivity was higher for females. The distribution by Graffar's method also yielded statistical significance. These analyses are described in Table 4.

FIGURE 1. Immunoglobulin M levels. Comparison between asthmatic patients and control

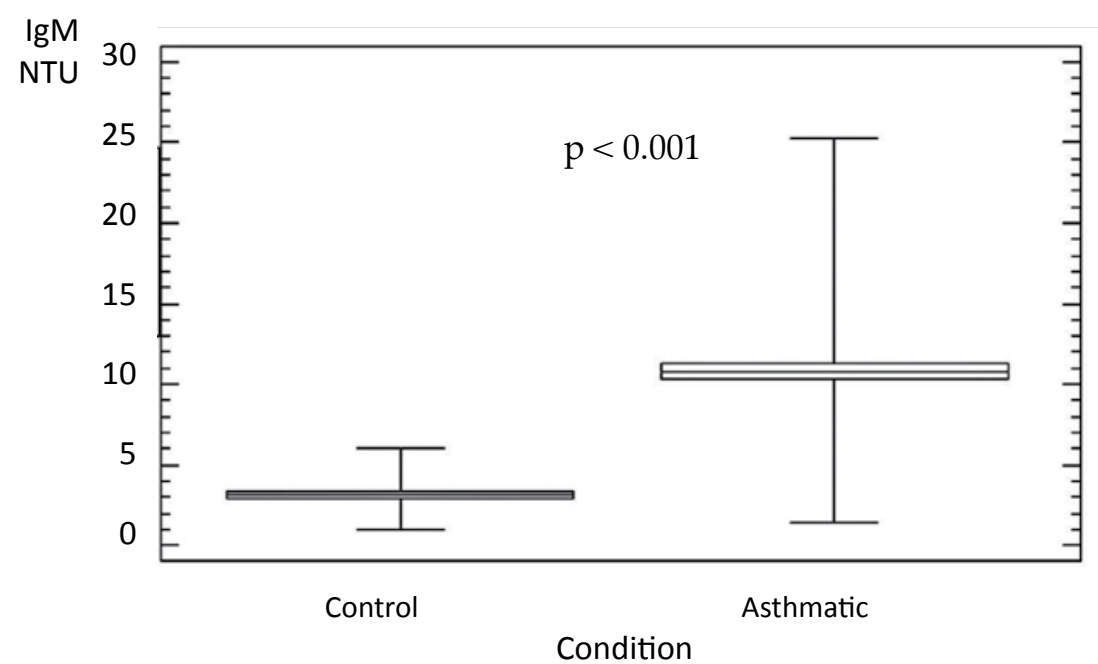

* Statistical significance $\mathrm{p}<0.001$. NTU (NovaTec units). IgM: immunoglobulin M.

TABLE 3. Statistically significant outcome measures related to specific immunoglobulin M level

\begin{tabular}{lccc}
\hline Outcome measures & $\mathbf{N}$ & Specific IgM levels (NTU)* & $\boldsymbol{P}^{* *}$ \\
\hline Control group & 50 & 3.1 & $0.0000^{*}$ \\
Asthmatic & 130 & 10.79 & $0.0001^{*}$ \\
Fever & & & \\
No & 110 & 10.01 & $0.0000^{*}$ \\
Yes & 20 & 15.03 & \\
Cough & & & $0.0000^{*}$ \\
No & 79 & 8.34 & \\
Yes & 51 & 14.58 & \\
Severity & & & $0.0000^{*}$ \\
Mild & 26 & 6.08 & \\
Moderate & 98 & 11.41 & \\
Severe & 06 & 21.12 & $0.0000^{*}$ \\
Crisis onset & & & \\
$<3$ hours & 87 & 12.94 & \\
$>$ 3 hours & 43 & 6.43 & \\
Hospitalization & & & \\
No & 33 & 12.45 & \\
Yes & 97 &
\end{tabular}

*: Average IgM. **: Highly significant, $\mathrm{p}<0.001$. NTU (NovaTec units).

IgM: immunoglobulin M. 


\section{DISCUSSION}

The association existing between acute MP infection and the severity of asthma exacerbation was observed in this study.

The relationship between respiratory infections and asthma has been described both in children and in adults. ${ }^{11,12}$

In a revision study, Metz et al. concluded that these agents were involved both in the exacerbations and in chronic asthma; therefore, these organisms were able to modify the severity of the condition, although their role in the development of asthma was not entirely identified. ${ }^{13}$

Biscardi et al. observed that MP infection was related to the onset and recurrence of exacerbations in asthmatic children. However, they were not able to establish a clear relationship nor the role of MP colonization in this

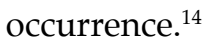

The prevalence found in this study was considered high (46\%), lower than Wood et al.'s report of $64 \%$ and much higher than that of other reports, which ranged between 3\% and 20\%. 13,15-17

Another important finding of our study was the highly significant association between asthma severity and MP infection, since prevalence was much higher in more severe cases than in cases of moderate exacerbation or in the controls.

Not all the studies agree on this association between exacerbation severity and IgM levels for MP. For example, in their study, Duenas et al. did not find significant differences when comparing the severity of the exacerbations with the positive MP result. ${ }^{18}$

In a prospective, case-control study performed on 82 patients, Iramain et al. showed a positive relationship between MP infection and exacerbation severity, and concluded that MP infection played an important role in the development of severe acute asthma. ${ }^{19}$

Likewise, in the prospective assessment of 58 patients with acute exacerbation, they found that specific IgM levels were much higher in patients with severe exacerbations both for MP and Chlamydophila pneumoniae. ${ }^{20}$

Studies associating the presence of MP in acute exacerbations with the risk of hospitalization were also contradictory.

Duenas et al. did not find differences between hospitalization risk and hospitalization days with MP positivity; hospitalization rate was $24.5 \% .^{18}$

In their study, Lieberman et al. analyzed the hospitalization risk among several atypical agents and concluded that only MP infected patients were actually at a higher risk. ${ }^{11}$

Another study found that children infected with MP or Chlamydophila pneumoniae who were not treated with macrolids presented higher recurrence and admission rates than those who received macrolids. ${ }^{21}$

The results of our research allowed us to determine that hospitalization rates were higher in children with high IgM levels.

MP is a tiny organism that is transmitted from one person to another through respiratory secretion drops which scatter in the air when coughing, and a close contact is needed for transmission to occur. Despite being asymptomatic, many individuals can keep on transmitting the organism for long periods of time..$^{22}$

The socioeconomic status classification of the population studied suggests, with statistical significance, an association between poverty, over-crowding and IgM positivity. There are no

TABLE 4. Outcome measures analysis as regards specific immunoglobulin M positivity or negativity

\begin{tabular}{|c|c|c|c|c|}
\hline \multirow[t]{2}{*}{ Outcome measures } & \multicolumn{3}{|c|}{ Specific IgM result } & \multirow[t]{2}{*}{$P^{*}$} \\
\hline & Positive & $\mathrm{n}(\%)$ & Negative & \\
\hline \multicolumn{5}{|l|}{$\overline{\text { Age }}$} \\
\hline 2-6 years old & $49(37.69)$ & & $57(43.85)$ & NS \\
\hline 7-12 years old & $11(8.46)$ & & $13(10.00)$ & \\
\hline \multicolumn{5}{|l|}{ Sex } \\
\hline Male & $20(15.38)$ & & $40(30.77)$ & 1 \\
\hline Female & $40(30.77)$ & & $30(23.08)$ & \\
\hline \multicolumn{5}{|l|}{ Graffar } \\
\hline II & - & & $1(0.77)$ & 2 \\
\hline III & $22(16.92)$ & & $45(34.62)$ & \\
\hline IV & $38(29.23)$ & & $24(18.46)$ & \\
\hline
\end{tabular}

$\mathrm{n}(\%)$; NS: not significant. 1. $\mathrm{X}^{2}=6.44 ; \mathrm{X}_{(1 ; 0.05)}^{2}=3.841$ with Yates' correction. $2 . \mathrm{X}^{2}=11.35 \mathrm{X}_{(2 ; 0.01)}^{2}=9.210$. IgM: immunoglobulin M. 
studies relating this outcome measure during acute asthma exacerbation, as it was done in this research.

An MP seroprevalence study evaluating overcrowding did not find any relationship between this outcome measure and seropositivity. ${ }^{23}$

The socioeconomic status of both populations (asthmatic vs. control) was exactly the same. Therefore, in addition to the socioeconomic factor, there must be some other factor in the asthmatic population, probably a higher level of asymptomatic carriers who increase the risk.

It has been mentioned that chronic MP infection increases asthma incidence, which is related to a poor disease control. The existing relationship between atopic MP infected patients has also been mentioned; this combination may contribute not only to the early development of asthma, but also to its persistence during adulthood..$^{24,25}$

This study was not able to confirm a relationship between the time since asthma diagnosis and specific IgM levels. There were no differences between patients with recently diagnosed asthma ( $<1$ year) and those who had been diagnosed a longer time ago ( $>3$ years).

An important finding in our results is the significant association between the time from the onset of the exacerbation and the presence of MP. No studies have related MP specific IgM with sudden-onset crisis and, opposite to the statement that infections were related to a slow onset, findings might suggest the likelihood of a mixed phenotype, including predominant bronchospasm followed by severe and potentially persistent inflammation.

It is known that toxins can be released during the course of an MP acute infection causing a toxic syndrome known as community-acquired respiratory distress syndrome (CARDS) that conditions epithelial damage and the activation of the immune response. Among MP infected patients, bronchial hyperresponsiveness can even be observed in non-atopic patients. Severe inflammation in the initial stages of the infection implies such infection has a role in the development of acute exacerbation. ${ }^{26-28}$

Some of this study's weaknesses are that it wasn't a multicenter study, which might have allowed for a larger sample size, and that it was not possible to investigate other infectious etiologies as exacerbation causes. For these reasons, prevalence cannot be generalized. Other studies in larger population groups should be carried out in order to obtain a microbiologic assessment and determine how the use of specific antibiotics affects acute asthma exacerbation during childhood.

To conclude, data suggest, in the first place, a high prevalence of MP disease within the sample of children with asthmatic exacerbations and, in the second place, a relationship between severe acute asthma exacerbation and MP infection. This might have therapeutic implications regarding the use of specific antibiotics against this atypical organism during the development of a severe exacerbation.

\section{REFERENCES}

1. Liao H, Yang Z, Yang C, et al. Impact of viral infection on acute exacerbation of asthma in out-patient clinics: a prospective study. J Thorac Dis 2016;8(3):505-12.

2. Papadopoulos N, Christodoulou I, Rohde G, et al. Viruses and bacteria in acute asthma exacerbations - A GA2LENDARE* systematic review. Allergy 2011;66(4):458-68.

3. Tan WC, Xiang X, Qiu D, et al. Epidemiology of respiratory viruses in patients hospitalized with near fatal asthma, acute exacerbations of asthma, or chronic obstructive pulmonary disease. Am J Med 2003;115(4):272-7.

4. Sutherland ER, Martin RJ. Asthma and atypical bacterial infection. Chest 2007;132(6):1962-6.

5. Hong SJ. The role of Mycoplasma pneumoniae infection in asthma. Allergy Asthma Immunol Res 2012;4(2):59-61.

6. Darveaux JI, Lemanske RF Jr. Infection-related asthma. J Allergy Clin Immunol Pract 2014;2(6):658-63.

7. Friedlander AL, Albert RK. Chronic macrolide therapy in inflammatory airways diseases. Chest 2010;138(5):1202-12.

8. MacDowell AL, Bacharier LB. Infectious triggers of asthma. Immunol Allergy Clin North Am 2005;25(1):45-66.

9. Bonillo Perales A, Romero González J, Picazo Angelín B, et al. Valor pronóstico y precisión de los indicadores de crisis asmática severa. An Esp Pediatr 1997;47(6):606-10.

10. Méndez CastellanoH.Proyecto Venezuela: Estudionacional de crecimiento y desarrollo humano de la República de Venezuela. Caracas: Ministerio de la Secretaria; 1996.

11. Lieberman D, Printz S, Ben-Yaakov M, et al. Atypical pathogen infection in adults with acute exacerbation of bronchial asthma. Am J Respir Crit Care Med 2003;167(3):406-10.

12. Johnston S, Martin R. Chlamydophila pneumoniae and Mycoplasma pneumoniae: a role in asthma pathogenesis? Am J Respir Crit Care Med 2005;172(9):1078-89.

13. Metz G, Kraft M. Effects of atipical infections with Mycoplasma and Chlamydia on asthma. Immunol Allergy Clin North Am 2010;30(4):375-85.

14. Biscardi S, Lorrot M, Marc E, et al. Mycoplasma pneumonia and asthma in children. Clin Infect Dis 2004;38(10):1341-6.

15. Wood PR, Hill VL, Burks ML, et al. Mycoplasma pneumonia in children with acute and refractory Asthma. Ann Allergy Asthma Immunol 2013;110(5):328-34.

16. Freymuth F, Vabret A, Brouard J, et al. Detection of viral, Chlamydia pneumoniae and Mycoplasma pneumonia infections in exacerbations of asthma in children. J Clin Virol 1999;13(3):131-9.

17. Maffey AF, Barrero PR, Venialgo $C$, et al. Viruses and atypical bacteria associated with asthma exacerbations in 
hospitalized children. Pediatr Pulmonol 2010;45(6):619-25.

18. Duenas Meza E, Jaramillo CA, Correa E, et al. Virus and Mycoplasma pneumoniae prevalence in a selected pediatric population with acute asthma exacerbation. J Asthma 2016;53(3):253-60.

19. Iramain R, De Jesús R, Spitters C, et al. Chlamydia pneumoniae, and mycoplasma pneumoniae: Are they related to severe asthma in childhood? J Asthma 2016;53(6):618-21.

20. Cosentini R, Tarsia P, Canetta C, et al. Severe asthma exacerbation: role of acute Chlamydophila pneumoniae and Mycoplasma pneumoniae infection. Respir Res 2008;9:48.

21. Esposito S, Blasi F, Arosio C, et al. Importance of acute Mycoplasma pneumoniae and Chlamydia pneumoniae infections in children with wheezing. Eur Respir J 2000;16(6):1142-6.

22. Wang K, Chalker V, Bermingham A, et al. Mycoplasma pneumoniae and respiratory virus infections in children with persistent cough in England: a retrospective analysis. Pediatr Infect Dis J 2011;30(12):1047-51.

23. Lezcano A, Balbaryski J, Torres F, et al. Seroprevalencia de anticuerpos anti-Mycoplasma pneumoniae: evaluación en niños menores de 12 años. Arch Argent Pediatr 2008;106(1):610.

24. Specjalski K, Jassem E. Chlamydophila pneumoniae, Mycoplasma pneumoniae infections, and asthma control. Allergy Asthma Proc 2011;32(2):9-17.

25. Cho Y, Ryu S, Choi M, et al. Asthma and allergic diseases in preschool children in Korea: findings from the pilot study of the Korean Surveillance System for Childhood Asthma. J Asthma 2014;51(4):373-9.

26. Medina J, Coalson J, Brooks E, et al. Mycoplasma pneumonia CARDS toxin exacerbates ovalbumin-induced asthma-like inflammation in BALB / c mice. PLoS One 2014;9(7):e102613.

27. Medina J, Coalson J, Brooks E, et al. Mycoplasma pneumonia CARDS toxin induces pulmonary eosinophilic and lymphocytic inflammation. Am J Respir Cell Mol Biol 2012;46(6):815-22.

28. Yano T, Ichikawa Y, Komatu S, et al. Association of Mycoplasma pneumoniae antigen with initial onset of bronchial asthma. Am J Respir Crit Care Med 1994; 149(5):1348-53. 